\title{
7 \\ Reducing Psychosocial Distress in Family Caregivers
}

\author{
Ann M. Steffen, Judith R. Gant, and Dolores Gallagher-Thompson
}

\section{Background}

Families remain the most common source of assistance for older adults with physical and/or cognitive limitations (National Alliance for Caregiving and the American Association of Retired Persons, 1997; Schulz \& Martire, 2004). A recent national phone survey found that nearly one in four US households included at least one selfidentified caregiver who gave unpaid assistance to an impaired or physically frail relative over the age of 50 (NAC/AARP, 1997). The term "caregiving" encompasses a wide range of activities, from management of medications and appointments to bathing, dressing, and toileting the individual. Typically, tasks change over time as the conditions in question either become more stable, deteriorate, or in some instances, improve. Family and friends often experience considerable stress when trying to provide extensive caregiving in addition to the other demands of their everyday lives - they are often referred to as the "sandwich generation" since many are caught in the middle between employment and the responsibilities of caring for their husbands and children (and perhaps grand-children), as well as the responsibilities of caring for an impaired parent or parent-in-law. Spouses also experience considerable distress, typically focusing on their sense of loss as changes occur in the marital relationship (Davidson, 2006). Although it is true that caregiving can occur in the context of any significant physical and/or emotional disorder, most of the intervention research has been conducted with relatives of older adults with Alzheimer's disease or another form of dementia. In addition, studies have found that these dementia family caregivers are generally more distressed than caregivers of physically impaired elders (Ory, Yee, Tennstedt, \& Schulz, 2000). Given space limitations, this chapter will focus on interventions with dementia family caregivers.

\section{Overview of Caregiver Distress: Why Do We Need Interventions for Caregivers?}

Multiple studies over the past 20 years have reported significant negative psychosocial impacts from long-term dementia caregiving. These include high 
rates of clinical depression and/or depressive symptoms (Gallagher, Rose, Rivera, Lovett, \& Thompson, 1989; Schulz \& Martire, 2004; Schulz, O’Brien, Bookwala, \& Fleissner, 1995), high rates of other negative emotions such as anger, frustration, burden, and fear (Ory et al., 2000), and other indices of distress, such as family conflict over caregiving, significant emotional strain, financial hardship, and reduced time for leisure pursuits (Ory et al.; Pinquart \& Sorensen, 2003). In addition, studies have reported negative effects of caregiving on the physical health of the primary caregiver. For example, Vitaliano et al. (2002) and Vitaliano, Young, and Zhang (2004) found that male caregivers had a greater prevalence of heart disease than noncaregiving men of the same age. Greater risk for high blood pressure and the metabolic syndrome were also reported. Others have found complaints of bodily aches and pains and greater prevalence of diabetes, allergies, and use of nonprescription pain medication to be common in dementia caregivers (Coon, et al., 2004; Pinquart \& Sorenson, 2003).

Numerous interventions have been developed to address these problems, and in the past decade, there have been multiple reviews published as to their efficacy (Bourgeois, Schulz, \& Burgio, 1996; Brodaty, Green, \& Koschera, 2003; Schulz, Martire, \& Klinger, 2005; Sorensen, Pinquart, \& Duberstein, 2002). It is difficult to compare results across reviews, however, because different criteria have been used at different times to establish treatments as "evidence-based." A recent review by Gallagher-Thompson and Coon (2007) that used strict criteria for identifying interventions as evidence-based found that three categories could be so considered at the present time; psychoeducational skill-building programs (e.g., Coon, Thompson, Steffen, Sorocco, \& Gallagher-Thompson, 2003); psychotherapy (e.g., Gallagher-Thompson \& Steffen, 1994); and multicomponent interventions (those using several distinct types of treatment such as support groups plus family meetings and case management; e.g., Mittleman, Roth, Coon, \& Haley, 2004; Zarit \& Zarit, 2007). Psychoeducational interventions, which derive from behavioral and cognitive theories and therapies (cf. Beck, Rush, Shaw, \& Emery, 1979; D'Zurilla, 1986; Lewinsohn, 1974; Lewinsohn, Munoz, Youngren, \& Zeiss, 1986) are often preferred by family members. The term is used to distinguish this kind of intervention from both traditional psychotherapy and from community-based support or educational programs. Most family caregivers, including the majority of those with diagnosable mental health conditions, do not identify themselves as candidates for psychotherapy or counseling. To appeal to these individuals, treatments are typically not labeled as individual or group psychotherapy; instead, such programs are often presented to caregivers with titles such as "skill training sessions" or "stress management classes" (Burgio, Hardin, Sinnott, Janosky, \& Hohman, 1995).

That said, it would also be well to add a note of caution here: most clinical researchers in this field recognize that there is no "one size fits all" intervention that will be successful. What type of intervention to use in a clinical setting, with a given caregiver, depends on the presenting problem, the care-recipient's stage of dementia, caregivers' coping strategies and general psychological and physical health, and available resources in the community. On a national level, attempts have been made 
to delineate different types of services that may be useful to caregivers at different points in the process - Coon, Ory, and Schulz (2004) describe five basic services included in the National Family Caregiver Support Program, a recently enacted piece of legislation that provides funding to the states for these services. They are information and referral, assistance with access to services, caregiver support, respite care, and supplemental services as needed. However, these services are not theory-driven; they are not grounded in the psychological or psychiatric literature, nor do they try to specify mechanisms of change.

In addition, most of the published reviews that have focused on developing an evidence base for $\mathrm{X}, \mathrm{Y}$, or $\mathrm{Z}$ treatment have failed to identify any one consistently effective method to reduce psychological distress, or improve well-being, in dementia family caregivers. It appears that types of distress and strain change considerably over time during the course of one's caregiving "career" and therefore the kinds of interventions that would successfully treat them also must change over time (Gallagher-Thompson \& Steffen, 1994; Gottlieb \& Wolfe, 2002; Zarit \& Zarit, 2007). For example, family therapy may be very helpful for certain problems, such as resolving interpersonal conflicts about what the diagnosis means (in early stages) or about placement decision-making (in later stages) (Arguelles, Klausner, Arguelles, \& Coon, 2004) whereas home-based behavioral and skill-building interventions may be effective for caregivers who are concerned about such latestage issues as safety in the home and who need help improving the physical and social components of the home environment (Gitlin \& Gwyther, 2004). Finally, few studies have included the care-recipient in the design; most focus solely on the primary caregiver, yet it is reasonable to assume that working with the dyad could significantly improve quality of life for both individuals. A notable exception to this can be found in the work of Linda Teri and colleagues (Teri, Logsdon, Uomoto, \& McCurry, 1997) in which caregivers were taught to decrease depression in the care-recipient by developing a program of shared pleasant events. A later study by this group showed the positive effects of regular mild exercise to improve mood of both caregiver and care-recipient (Teri et al., 2003). In addition, a later chapter in this volume (Fisher, Drossel, Ferguson, Cherup, \& Sylvester, 2007) addresses this issue in depth. Readers interested in the application of behavioral and cognitive interventions to demented persons who reside in nursing homes (where paid, not family, caregivers are typically involved) are referred to a recent book on issues in long-term care consultation and intervention (Hyer \& Intrieri, 2006). For the purposes of this chapter, we will focus on description of behavioral and cognitive psychoeducational approaches, where the evidence base is strong for their application to community-dwelling family caregivers.

\section{Diversity Issues in Intervention Research}

Ethnic and cultural differences are also extremely important in the choice of intervention. There are two large-scale multisite studies called the Resources for Enhancing Alzheimer's Caregivers Health (REACH) projects that can be used to 
guide the choice of effective interventions. These studies were conducted with significant numbers of Black/African American and Hispanic/Latino caregivers (in addition to Caucasian/Anglo caregivers) to evaluate what kind of intervention program(s) would be effective with these groups (see Schulz et al., 2003, for overall description of the first REACH project). Several publications from these studies may be of interest to the reader; for example, in the first REACH study, two sites enrolled Hispanic/Latino caregivers and four sites enrolled African Americans - in addition to Caucasians. The Palo Alto CA site enrolled primarily Mexican Americans; at the Miami FL site, Cuban Americans were the focus. Each site found that the interventions they chose to use (psychoeducational skill building at Palo Alto and family therapy plus technological support at Miami) were very effective with the non-Caucasians to reduce depression and increase use of positive coping strategies (Eisdorfer et al., 2003; Gallagher-Thompson, Coon, Solano, Ambler, Rabinowitz, \& Thompson, 2003). At the Alabama site, a psychoeducational program that focused on teaching skills for managing problematic behaviors of the care-recipient was successful with African Americans (Burgio, Stevens, Guy, Roth \& Haley, 2003), and at the Philadelphia site, an occupational-therapy-based in-home intervention program that taught home safety and environmental modification was also successful with African Americans (Gitlin et al., 2003). Note that these programs were "tailored" to be ethnically and culturally appropriate (Gallagher-Thompson et al.) and at the sites serving Hispanic/Latino caregivers, interventions were conducted in Spanish as well as English. In the second REACH study, the most successful interventions from the first project were used to create a single, multicomponent intervention that was done in the same way across sites. It included teaching skills for stress management and management of problematic care-recipient behaviors, modifying negative thoughts about caregiving, and increasing everyday pleasant events. Over 600 new ethnically diverse caregivers participated; results indicated that, compared to the control condition, those in the active intervention were significantly more improved in several quality of life indicators. This was true in both the Hispanic/Latino and Caucasian groups, regardless of relationship. In the African Americans, spouse caregivers improved more than daughters or other relatives (REACH II investigators, 2006).

Taken together, results of the second REACH project and the GallagherThompson and Coon (2007) review strongly support the conclusion that both psychoeducational skill-building interventions (such as those focused on behavior management, depression management, etc.,) and some specific multicomponent interventions that include several distinct approaches can currently be considered evidence based. This evidence base extends beyond Caucasian caregivers (to Hispanic/Latinos and Black/African Americans), although empirical studies with other ethnic groups (e.g., Asian groups such as Chinese, Filipino, Japanese, and Asian Indian caregivers) remains to be conducted. Individuals interested in clinically oriented information about working with diverse family caregivers are referred to Yeo and Gallagher-Thompson (2006). 


\section{Assessment Issues and Recommendations}

Clinicians who work with family caregivers of cognitively impaired older adults would do well to conduct an assessment of mental health symptoms, such as depression and anxiety levels, before initiating treatment. Such assessments can be done again, during treatment, to measure change. Scales such as the Center for Epidemiological Studies - Depression self-report measure of symptoms (Radloff, 1977) has been used in much of the clinical research discussed here, as well as in practice. It has clear cutoff scores to help determine if depression is in a clinical range, which can be helpful to indicate if a referral for more intensive psychiatric or psychological treatment is needed. In addition, the Revised Memory and Behavior Problem Checklist (Teri et al., 1992) asks caregivers to report whether the care-recipient displayed a number of specific problem behaviors over the past week (i.e., memory related behaviors such as repeating questions, or disruptive behaviors such as yelling, and depressive behaviors, such as being tearful). If the caregiver endorses the item, then he/she is asked to rate level of distress or "bother" it caused on a Likert scale of 0 , not at all, to 4, extremely. Some studies have also found that self-efficacy (at baseline) is an important moderator of treatment effects (Rabinowitz et al., 2006). It can be assessed readily with the Revised Caregiver Self-Efficacy Scale (Steffen, McKibbin, Zeiss, Gallagher-Thompson, $\&$ Bandura, 1997) which asks caregivers to rate their confidence that they can ask for respite, respond effectively to problem situations with the care-recipient, and control upsetting thoughts about caregiving. Changes in self-efficacy as a function of treatment may also serve to mediate change in outcome measures and treatment responsiveness; this remains to be explored. Other measures to consider include: positive aspects of caregiving (Tarlow et al., 2004); religious coping (which may be particularly relevant for ethnically diverse caregivers; Pargament, Koenig, \& Perez, 2000), and overall quality of life. The interested reader is referred to the review chapter by Gottlieb, Thompson, and Bourgeois (2004) for discussion of these and other assessment tools.

We would like to recommend that in addition to assessing the caregiver, it would be wise to also evaluate cognitive and behavioral functioning in the care-recipient. Many times, however, professionals do not have direct access to the care-recipient, and will need to rely on caregivers' reports to understand care-related challenges and demands. The Index of Activities of Daily Living Scale (Katz, Ford, Moskowitz, Jackson, \& Jaffe, 1963) provides information concerning care-recipients' levels of functional impairments, with each item reflecting a type of more severe disability common in late-stage dementia (e.g., inability to bathe or toilet oneself). There is also a measure of the Instrumental Activities of Daily Living (Lawton \& Brody, 1969) tapping into such domains as medication management, ability to remember and keep appointments, and to find one's way outside the home. It is useful with early stage patients. As noted above, the checklist inquiring about memory and behavior problems can also be helpful to determine the level of "objective" burden of the caregiver. 
Besides the use of these kinds of psychometric scales or questionnaires, we note that behavioral and cognitive methods emphasize the role of specificity in identifying goals for intervention. With that in mind, we also suggest use of an idiographic assessment tool that allows for the measurement of problem areas specific to individual caregivers. For example, many of our studies have used some variant of a target complaints interview where caregivers are asked "As you think about your caregiving situation, what are the three things that are most stressful for you to deal with?" Then, for each of the three situations described, the caregiver is asked to rate the degree to which the situation was accompanied by negative feelings (e.g., upset, sadness, frustration, or irritation, on a Likert scale of 1 , not at all, to 5, extremely). These ratings can then be averaged across the three situations to yield a summary score and at the end of the intervention program, ratings can be obtained again for those specific problem areas. Change in each domain, or in the overall summary score, indicates that the caregivers' particular concerns were addressed satisfactorily.

\section{Case Examples}

In the two descriptions that follow we describe a combination of behavioral (behavioral activation, behavioral management, relaxation training) and cognitive (challenging negative thinking, re-appraising the situation, and cognitive restructuring) interventions.

\section{Case Study \#1: Brendan}

Here we describe assessment and skills training (taking about 20 weeks) with a male spousal caregiver. Brendan, age 77, was taking care of his wife, Alice, 76, who was diagnosed with Alzheimer's disease. He characterized her general health as poor, including impaired eyesight and unsteady walking. Brendan had the academic equivalent of an associate degree. As a retiree, he reported financial difficulty paying for the basics, including groceries, medicines, and medical care. Their married daughter Anne worked mornings and was reported to be quite helpful with her mother's care. Brendan identified bathing as the one functional domain in which Alice required significant assistance. He indicated that it was "somewhat difficult" for Alice to understand simple instructions and to find her way around the house; it was "quite a bit difficult" for her to remember recent events and speak sentences, and "very difficult" for her to know what day of the week it is and to remember her home address. On the Revised Memory and Behavior Problem Checklist, Brendan's average upset score was 2.17, meaning that he was "moderately" or more upset with the ten disruptive behaviors Alice had shown in the past week. On the Target Complaint interview, Brendan's complaint of "her slowness" had the highest average score across the four emotions (upset, sadness, frustration, and irritation); he endorsed the word "moderately" for each of the emotions. 
The first three sessions focused on behavioral activation as a preventive and intervention skill for managing depressed mood in himself and in Alice. Efforts were made to link daily mood ratings to a daily pleasant event log; this was done with between-session assignments of increasing favorite activities and monitoring daily mood for himself and Alice. Secondary skills included simplifying communication with his wife (including "going along with her view of what's happening" and "avoid trying to argue or convince"), and keeping track of specific caregiving stressors with a daily monitoring form. Brendan made the connection that some specific activities (going to church, having lunch with church friends, and a visit from their daughter) were especially enjoyable and linked to higher mood ratings on those days. Time in session was also devoted to identifying and modifying thoughts that held him back from increasing pleasant events for both himself and Alice. In Sessions 4-7, skills for managing difficult behaviors were taught and reinforced, including identifying patterns of antecedents and consequences. For example, Alice's repeated questioning was discovered to be most common in the late morning and late afternoon, times when he realized that she was probably bored and he was attempting to take care of household responsibilities. To reduce the frustration he felt during these incidents, he began to plan specific times to begin a new joint activity, including sub-tasks related to household chores. He realized that it would also be important for him to plan out more activities (like listening to gospel music) for Alice to do by herself at times when he was occupied with his own chores and hobbies.

Sessions 8-10 focused on relaxation training, including development of the skills to recognize physical signs of frustration ("danger signals") and use of controlled breathing techniques to prevent or reduce strong feelings of anger and frustration. These were especially relevant for Brendan because his treatment goals included "dealing with anger." He realized that his danger signals were feelings of impatience, his thought "why can't she remember?," his mind racing, and sighing. He liked the suggested idea of visualizing a huge stop sign, saying "STOP, calm down and do controlled breathing." Between Sessions 8 and 9, Brendan completed six practice sessions using the controlled breathing exercise, and showed improved tension scores after four of the six practices. A final didactic session included home safety precautions and financial and legal issues, in addition to program summary and development of a maintenance plan. A key theme identified by Brendan was his need to give himself credit for "trial and error" approaches to problem solving, rather than expecting a single solution to always work. During his two later maintenance sessions, each scheduled 1 month apart, he identified the focus on pleasant events, and the controlled breathing relaxation exercises, as most helpful. He said that he had improved self-control and decreased anger, so he was pleased that he had moved closer to meeting the goals he had set at the beginning of the program.

Brendan's postintervention and 10-month outcome scores were compared with his baseline scores. Despite the continued progression of his wife's dementia, on the Revised Memory and Behavior Checklist Brendan's scores on all behavior problems showed improvement from "moderate" (upset or annoyance) to "a little," 
which we consider to be a clinically significant improvement. Brendan demonstrated both substantial decreases in his levels of distress and uniform maintenance of these gains. While Brendan's positive affect decreased somewhat from preintervention to 10 week postintervention, his negative affect improved substantially. This posttreatment negative affect reduction is consistent with Brendan's decreased upset and annoyance over Alice's behavior problems. Brendan demonstrated steady improvement in his self-efficacy outcome scores, with a 37-point improvement on the managing behavioral problems subscale. In the preintervention "Target Complaints Interview," Brendan had chosen "her slowness" as the most stressful part of caregiving at baseline. The other two target complaints were "making meals" and "taking her out." By the time of the posttest, he no longer considered her slowness or making meals a problem, but taking her out was still stressful; on the other hand, when asked how upset, sad, frustrated, or irritated these three stressors made him feel, he said "not at all." At the 10-month assessment, making meals was the only one of the three stressors that he still considered to be a problem. For all three of the stressors, he endorsed being "a little" (2.0) distressed (upset, sad, frustrated, or irritated) on three of four of the feelings.

\section{Case Study \# 2: Esther}

Esther is a 52-year-old Latino woman who graduated from high school, is the mother of three teen-aged girls, and who lives with her husband, works parttime outside the home in an office setting, and takes care of her 75-year-old mother, who also lives with them and has been demented for about 8 years. Her mother Rosa is a Type II diabetic and not reliable about checking blood sugar or taking medication. Esther was extremely stressed at the initial evaluation: her self-reported depression on the CES-D was 20, which is at the low end of the clinical range, and she reported multiple problems taking care of her mother and dealing with ongoing stress at work and at home. She rated her overall stress as "extreme" and was very motivated to participate in the small-group intervention program we were conducting. It was offered in a community setting near her home, in the evenings so that she could attend after work, and was conducted in Spanish: although she spoke English well, she said she preferred to be in the Spanish-speaking group, because otherwise it would be difficult to share personal information and feelings. After signing informed consent, Esther enrolled in a 12-week "Coping with Caregiving" skills training research program. An array of skills was taught, beginning with cognitive restructuring. Members of the group were asked to note thoughts that were related to stressful situations during the week and bring that information back to share next time. Esther reported many negative thoughts having to do with her inadequacy as a caregiver; these were associated with strong feelings of guilt, that she was not doing enough for her mother. She was very "hard on herself" in that she expected to come home from work and not be irritable with her mother, even though Rosa was very dependent on her and seemed to resent time she spent with her husband and daughters (who also demanded her attention). In the group she was encouraged to 
(gently) challenge these thoughts: she was asked questions such as: "how much is enough?" and "what else could you be doing, that you are not doing, that would help your mother?"

In the first month this was the focus of the Coping Class: Esther learned not only to be more realistic about what she could and could not do for her mother, but she also learned to help others challenge their unrealistic thoughts as well. For example, Josefina was very tearful and depressed over how quickly her husband's dementia seemed to be progressing. She was longing for things to be "the way they used to be" with him. Esther helped her to see that, although those days were gone, Josefina could still try to make a good life with her husband as he was now. Josefina was comforted by that point of view: all was not lost. There were still things her husband could do, and things that they could do together. This in turn helped to reinforce Esther's understanding that changing negative thinking made a real difference in her life; that skill she continued to use on a regular basis.

The group then focused on the skill of learning to manage common problem behaviors in their care-receivers: either by changing antecedents, or by changing their reactions and responses to the problem behaviors. Esther, for example, reacted very strongly when her mother became upset with her and yelled at her. Esther often cried herself to sleep, and did not know what to do to handle the situation. The group suggested that she develop a plan to do shared pleasant activities with her mother. Normally this coping class emphasizes developing pleasant events for oneself, but since Esther was so busy, and had so little time to herself, we shifted the goal to include positive time with Rosa. The hypothesis was that Rosa was becoming upset because she was feeling ignored by Esther, so if Esther would take her mother's hand, for example, and the two of them go for a short walk together, perhaps that would make a difference. It did, in fact, improve the overall quality of life in the home, and enabled Esther to realize that many other things could also bring pleasure to her mother - such as looking at old photo albums together, or listening to her mother sing church hymns in Spanish (which she loved to do).

In an effort to get the teen-aged daughters involved, the group suggested this strategy: arrange for them to spend some time with their grandmother and ask her to tell them stories of her early life in Mexico. This suggestion did not always work since the girls were busy with their own lives, but they began to do it about once a week, more or less. The importance of "la familia" (a strong cultural value in Latino groups) reinforced their willingness to participate.

By the eighth session, the coping class focused on communication skills: with non-Latinos, we refer to this as "assertiveness training" but focus groups conducted before the intervention study began revealed that this was not the correct terminology to use with this cultural group. Instead, we called this "learning to communicate more effectively" and that was well received. The focus was, first, on communicating with the care-recipient's primary doctor, and then on communicating with others (family, friends) to get respite help. To address the first aim, caregivers were given checklists of questions to bring up, and were encouraged to fill out specifics before the next doctor's appointment. 
This was done as an in-class exercise. Esther reported that this was very helpful, since when she took her mother to the doctor, she usually was harried, and could not think clearly about key issues to discuss. The class then used role playing to help participants practice how to ask for "respite" help: time off from their regular caregiving to take care of other matters. Esther had a particularly difficult time with this: she was quite timid in the role play exercises, and did not ask clearly for what she needed (as was the case with most of the women in the group). Over the next 2 weeks, she became more comfortable by practicing with other class members, but Esther was still quite anxious about the "homework" assignment of actually asking someone to take care of her mother for a couple of hours so that she could get to a much-needed dental appointment. The first time she asked (a cousin who lived nearby) she was turned down; then she talked it over with her eldest daughter, and quite unexpectedly, the daughter agreed. She said she could skip some particular after-school activity that she liked to do once in awhile so that her mother could get to the dentist. This was an important experience because it taught Esther that if she did not ask, she would not get the help and support she needed; on the other hand, if she did ask, clearly and constructively, at least there was a chance that the request would be granted.

The final weeks focused on future transitions: how to recognize when the care-recipient may need more care than the family can provide. Also included was a discussion of end-of-life issues: preparing for the inevitable final transition. Most of the caregivers in this 6-person class were grateful that these issues were brought up; they said that at home, and in their culture, these kinds of things generally were not talked about openly. To facilitate discussion with other family members, class leaders provided each member with an "Advance Directive" kit in Spanish or English, and one of the homework assignments was to begin to discuss this concrete topic with another family member. Most caregivers talked with their priest or clergyperson, rather than family; once that individual approved (so to speak) of the content, then they were more able to approach family directly. Esther found that she was "too emotional" to face this, but she did encourage others in the group to do so. She said that she would pray and ask for help.

At the conclusion of the coping class, Esther's depression score on the CES-D was below 10, indicating that she was no longer having significant symptoms. More importantly, her overall stress rating was much lower (dropped by 10 points from the "pre" evaluation) and she reported being less "bothered" by her mother's behavior since she felt more confident that she could respond appropriately (most of the time). At the 6 month follow-up, Esther had maintained her gains in terms of low psychological distress, and said that she was talking with her priest about some of the end-of-life issues that were raised in the class. She was very appreciative for the opportunity to be in the project, and in fact referred several others. Overall, it appears that the "coping class" psychoeducational skill-building approach, when delivered in a culturally competent manner, and in a small-group context, was very effective for Esther. 


\section{Directions for Future Research}

As noted above, this chapter focused on the use of evidence-based interventions with dementia family caregivers. Much more research is needed on interventions helpful to caregivers of adults with other chronic illnesses, such as cancer, diabetes, stroke, heart disease, and the like. Reviews by Given, Given, Kozachik, and Rawl (2003), Biegel and Schulz (1999), and Toseland et al. (2001) can be helpful in that regard. Indeed, treatment studies with other populations of caregivers appear to have fallen behind in terms of both quantity of investigations, as well as research sophistication.

Research has demonstrated a subject selection bias in caregiver studies conducted in university and medical settings (Dura \& Kiecolt-Glaser, 1990). Family caregivers willing to go to a university or medical setting for assessments were less depressed and less emotionally distressed than those who were willing to be interviewed only in their home. One could extend these findings and expect that treating only those able and willing to attend weekly sessions in the community restricts the generalizability of study results. This is particularly true of group approaches in which sessions are not easily rescheduled. At this point, most skills-based interventions depend upon caregivers' ability and interest in attending consecutive weekly sessions in the community. This is an unfortunate trend because there are a number of circumstances in which this may be difficult, and caregivers are consequently prevented from receiving needed assistance. For example, it is unlikely that such interventions can routinely be offered in rural communities because of the distance and inconvenience for caregivers.

Changes in technology have opened up new possibilities for administering caregiver interventions to those whose caregiving responsibilities might hinder their participation (Buckwalter, Davis, Wakefield, Kienzle, \& Murray, 2002; Steffen, Mahoney, \& Kelly, 2003). The telephone has long been used by clinicians providing referrals and crisis intervention, and has more recently been used as the primary mechanism for treatment delivery (Haas, Benedict, \& Kobos, 1996; Mermelstein \& Holland, 1991). Likewise, investigators have explored the use of videotapes as part of cognitive-behavioral interventions. Videotapes have been used for psychoeducational purposes in primary care (Robinson, Katon, Von Korff, \& Bush, 1997), and to provide education and modeling for individuals with public speaking anxiety (Ayres, Ayres, Baker, \& Colby, 1993). A small preliminary study conducted by our research group suggests that a cognitivebehavioral treatment for distressed caregivers can be effective when delivered through videotapes, workbook, and telephone sessions with intervention staff (Steffen, 2000). We are currently in the process of testing a revised version of this video intervention with a larger group of dementia family caregivers, across nine states, with the goal of reducing depression levels in caregivers (Steffen \& Mangum, 2003). Chang (1999) has also demonstrated the effectiveness of a videotape and telephone intervention to train caregivers in behavioral strategies. Over 
the next decade of caregiver intervention research, we expect to see increased attention to how technology can be used to deliver effective behavioral and cognitive treatments.

Two other issues deserve more attention in future research: first, it is not clear that any of the evidence-based interventions we have presented have any positive, discernible impact on the physical health and well-being of the caregiver. Yet caregivers can, themselves, have chronic health conditions (such as diabetes, heart disease, and hypertension) that may be exacerbated by severe stress. As Schulz and Beach (1999) reported, spousal caregivers who said they were significantly stressed were more likely to die during the course of a 4-year follow - up than caregivers with low stress. While these findings need to be replicated, they point to the very heavy negative toll that may occur in some people who are not able to manage stress well.

The second issue concerns the paucity of research on ethnic and culturally diverse caregivers: although the REACH studies have laid a good foundation, most of the ever-increasing ethnic minority groups in this country have not participated in caregiver intervention research projects. Yet caregiving expectations, coping strategies, and perceived stress are all filtered through the lens of culture (Aranda \& Knight, 1997), and culturally competent research is needed to address the needs of the varied ethnic groups in our country. This is a two-sided issue: investigators and clinicians need to develop culturally relevant interventions, and then conditions need to be fostered so that diverse caregivers will enroll in the projects, or use the services provided. There are many factors that may account for the inherent difficulties in designing and executing research and clinical projects with this kind of focus, such as linguistic challenges and low literacy levels (even in the language of one's country of origin). In addition, there may be specific cultural values and beliefs that make it difficult for caregivers to seek help. In many cultural groups, signs and symptoms of dementia are regarded as "normal aging" or as part of severe mental illness, leading to stigmatization, and reluctance to seek help outside the family (Hinton, Fox, \& Levkoff, 1999). Allery et al. (2004), with sponsorship from the Alzheimer's Association, have issued a "call to action" on this topic. Clearly, given the increasing longevity of the US population, and its increasing diversity, this is an issue that we can no longer ignore in our research applications and in our clinical practice.

Acknowledgments. Preparation of this chapter was supported in part by grant \# MH061956-03 from the National Institute of Mental Health and grant \# IRG-03-5987 from the national office of the Alzheimer's Association to Dr. Steffen; funding from the Missouri Alzheimer's and Related Disorders Program to Dr. Gant, and grants \# AG 18784 and AG 13289 from the National Institute on Aging, and grant \#IIRG-04-1109 from the national office of the Alzheimer's Association to Dr. Gallagher-Thompson. 


\section{References}

Allery, A. J., Aranda, M. P., Dilworth-Anderson, P., Guerrero, M., Haan, M., Hendrie, H., et al. (2004). Alzheimer's disease and communities of color. In K. E. Whitfield (Ed.), Closing the gap: Improving the health of minority elders in the new millennium (pp. 81-86). Washington, DC: Gerontological Society of America.

Aranda, M., \& Knight, B. (1997). The influence of ethnicity and culture on the caregiving stress and coping process: A sociocultural review and analysis. The Gerontologist, 37, 342-354.

Arguelles, S., Klausner, E., Arguelles, T., \& Coon, D. W. (2004). Family interventions to address the needs of the caregiving system. In D. W. Coon, D. Gallagher-Thompson, \& L. W. Thompson (Eds.), Innovative interventions to reduce dementia caregiver distress: A clinical guide (pp. 99-118). New York: Springer.

Ayres, J., Ayres, F., Baker, A., \& Colby, N. (1993). Two empirical tests of a videotape designed to reduce public speaking anxiety. Journal of Applied Communication Research, 21, 132-147.

Beck, A. T., Rush, A. J., Shaw, B., \& Emery, G. (1979). Cognitive therapy of depression. New York: Guilford Press.

Biegel, D. E., \& Schulz, R. (1999). Caregiving and caregiver interventions in aging and mental illness. Family Relations: Interdisciplinary Journal of Applied Family Studies, 48, 345-354.

Bourgeois, M. S., Schulz, R., \& Burgio, L. (1996). Interventions for caregivers of patients with Alzheimer's disease: A review and analysis of content, process, and outcomes. International Journal of Aging and Human Development, 43, 35-92.

Brodaty, H., Green, A., \& Koschera, A. (2003). Meta-analysis of psychosocial interventions for caregivers of people with dementia. Journal of the American Geriatrics Society, 51, 657-664.

Buckwalter, K. C., Davis, L. L., Wakefield, B. J., Kienzle, M. G., \& Murray, M. A. (2002). Telehealth for elders and their caregivers in rural communities. Family and Community Health, 25, 31-40.

Burgio, L. D., Hardin, M., Sinnott, J., Janosky, J., \& Hohman, M. J. (1995). Acceptability of behavioral treatments and pharmacotherapy for behaviorally disturbed older adults: Ratings of caregivers and relatives. Journal of Clinical Geropsychology, 1, 19-32.

Burgio, L., Stevens, A., Guy, D., Roth, D. L., \& Haley, W. E. (2003). Impact of two psychosocial interventions on white and African American family caregivers of individuals with dementia. The Gerontologist, 43, 568-579.

Chang, B. L. (1999). Cognitive-behavioral intervention for homebound caregivers of persons with dementia. Nursing Research, 48, 173-182.

Coon, D. W., Ory, M., \& Schulz, R. (2004). Family caregivers: Enduring and emergent themes. In D. W. Coon, D. Gallagher-Thompson, \& L. W. Thompson (Eds.), Innovative interventions to reduce dementia caregiver distress: A clinical guide (pp. 3-27). New York: Springer.

Coon, D. W., Rubert, M., Solano, N., Mausbach, B., Kraemer, H., Arguelles, T., et al. (2004). Well-being, appraisal, and coping in Latina and Caucasian dementia family caregivers: Findings from the REACH study. Aging and Mental Health, 8, 330-345.

Coon, D. W., Thompson, L., Steffen, A., Sorocco, K., \& Gallagher-Thompson, D. (2003). Anger and depression management: Psychoeducational skill training interventions for women caregivers of a relative with dementia. The Gerontologist, 43, 678-689.

Davidson, A. (2006). A curious kind of widow: Loving a man with advanced Alzheimer's. McKinleyville, CA: Fithian Press. 
Dura, J. R., \& Kiecolt-Glaser, J. K. (1990). Sample bias in caregiving research. Journal of Gerontology: Psychological Sciences, 45, P200-P204.

D'Zurilla, T. (1986). Problem solving therapy: A social competence approach to clinical intervention. New York: Springer.

Eisdorfer, C., Czaja, S., Loewenstein, D. A., Rubert, M. P., Arguelles, S., Mitrani, V., et al. (2003). Effect of a family therapy and technology-based intervention on caregiver depression. The Gerontologist, 43, 521-531.

Fisher, J. E., Drossel, C., Ferguson, K., Cherup, S., \& Sylvester, M. (2007). Functional analysis for treating behavioral problems in individuals with dementia. In D. GallagherThompson, A. M. Steffen, \& L. W. Thompson (Eds.) Handbook of behavioral and cognitive therapies with older adults. New York: Springer.

Gallagher, D., Rose, J., Rivera, P., Lovett, S., \& Thompson, L. W. (1989). Prevalence of depression in family caregivers. The Gerontologist, 29, 449-456.

Gallagher-Thompson, D., \& Coon, D. W. (2007). Evidence-based psychological treatments for distress in family caregivers of older adults. Psychology and Aging 22(1), 37-51.

Gallagher-Thompson, D., Coon, D. W., Solano, N., Ambler, C., Rabinowitz, Y., \& Thompson, L. W. (2003). Change in indices of distress among Latina and Anglo female caregivers of elderly relatives with dementia: Site specific results from the REACH National Collaborative Study. The Gerontologist, 43, 580-591.

Gallagher-Thompson, D., Haley, W., Guy, D., Rubert, M., Arguelles, T., Zeiss, L., et al. (2003). Tailoring psychological interventions for ethnically diverse family caregivers. Clinical Psychology: Science and Practice, 10, 423-438.

Gallagher-Thompson, D., \& Steffen, A. (1994). Comparative effects of cognitive/behavioral and brief psychodynamic psychotherapies for depressed family caregivers. Journal of Consulting and Clinical Psychology, 62, 543-549.

Gitlin, L. N., \& Gwyther, L. P. (2004). In-home interventions: Helping caregivers where they live. In D. W. Coon, D. Gallagher-Thompson, \& L. W. Thompson (Eds.), Innovative interventions to reduce dementia caregiver distress: A clinical guide (pp. 139-160). New York: Springer.

Gitlin, L. N., Winter, L., Corcoran, M., Dennis, M. P., Schinfeld, S., \& Hauck, W. (2003). Effects of the home environmental skill-building program on the caregiver-care recipient dyad: 6 month outcomes from the Philadelphia REACH initiative. The Gerontologist, 43, 532-546.

Given, B., Given, C. W., Kozachik, S., \& Rawl, S. (2003). Family caregiving interventions in cancer care. In C. Given, B. Given, V. Champion, S. Kozachik, \& D. DeVoss (Eds.), Evidence-based cancer care and prevention: Behavioral interventions (pp. 332-370). New York: Springer.

Gottlieb, B. H., Thompson, L. W., \& Bourgeois, M. (2004). Monitoring and evaluating interventions. In D. W. Coon, D. Gallagher-Thompson, \& L. W. Thompson (Eds.), Innovative interventions to reduce dementia caregiver distress: A clinical guide (pp. 28-49). New York: Springer.

Gottlieb, B. H., \& Wolfe, J. (2002). Coping with family caregiving to persons with dementia: A critical review. Aging and Mental Health, 6, 325-342.

Haas, L. J., Benedict, J. G., \& Kobos, J. C. (1996). Psychotherapy by telephone: Risks and benefits for psychologists and consumers. Professional Psychology: Research and Practice, 27, 154-160.

Hinton, W. L., Fox, K., \& Levkoff, S. (1999). Exploring the relationships among aging, ethnicity, and family dementia caregiving. Culture, Medicine and Psychiatry, 23, 403-413. 
Hyer, L., \& Intrieri, R. (2006). Geropsychological interventions in long-term care. New York: Springer.

Katz, S., Ford, A., Moskowitz, R., Jackson, B., \& Jaffe, M. (1963). Studies of illness in the aged: The index of ADL, a standardized measure of biological and psychosocial function. Journal of the American Medical Association, 185, 914-919.

Lawton, M. P., \& Brody, E. (1969). Assessment of older people: Self-maintaining and instrumental activities of daily living. The Gerontologist, 9, 179-186.

Lewinsohn, P. (1974). A behavioral approach to depression. In R. Friedman \& M. Katz (Eds.), The psychology of depression: Contemporary theory and research (pp. 157-176). New York: Wiley.

Lewinsohn, P., Munoz, R., Youngren, M., \& Zeiss, A. M. (1986). Control your depression (2nd ed.). Englewood Cliffs, NJ: Prentice-Hall.

Mermelstein, H. T., \& Holland, J. C. (1991). Psychotherapy by telephone: A therapeutic tool for cancer patients. Psychosomatics, 32, 407-412.

Mittleman, M., Roth, D., Coon, D. W., \& Haley, W. E. (2004). Sustained benefit of supportive interventions for depressive symptoms in caregivers of patients with Alzheimer's disease. American Journal of Psychiatry, 161, 850-856.

National Alliance for Caregiving/American Association of Retired Persons. (1997). Family Caregiving in the U.S: Findings from a national survey. Bethesda, MD: National Alliance for Caregiving.

Ory, M. G., Yee, J. L., Tennstedt, S. L., \& Schulz, R. (2000). The extent and impact of dementia care: Unique challenges experienced by family caregivers. In R. Schulz (Ed.), Handbook on dementia caregiving: Evidence-based interventions for family caregivers (pp. 1-32). New York, NY: Springer.

Pargament, K., Koeniz, H.G., \& Perez, L. M. (2000). The many methods of religious coping: Development and initial validation of the RCOPE. Journal of Clinical Psychology, 56, 519-543.

Pinquart, M., \& Sorensen, S. (2003). Differences between caregivers and non-caregivers in psychological health and physical health: A meta-analysis. Psychology and Aging, 18, 250-267.

Rabinowitz, Y., Mausbach, B., Coon, D. W., Depp, C., Thompson, L.W., \& GallagherThompson, D. (2006). The moderating effect of self-efficacy on intervention response in women family caregivers of older adults with dementia. American Journal of Geriatric Psychiatry, 14, 676-683.

Radloff, L. (1977). The CES-D scale: A self-report depression scale for research in the general population. Applied Psychological Measurement, 1, 385-401.

REACH II investigators (alphabetically: Belle, S., Burgio, L., Burns, R., Coon, D., Czaja, S., Gallagher-Thompson, D., Gitlin, L., Klinger, J., Koepke, K. M., Lee, C. C., Martindale-Adams, J., Nichols, L., Schulz, R., Stahl, S., Stevens, A., Winter, L. \& Zhang, S.). (2006). Enhancing the quality of life of dementia caregivers from different ethnic or racial groups: A randomized, controlled trial. Annals of Internal Medicine, 145, 727-738.

Robinson, P., Katon, W., Von Korff, M., \& Bush, T. (1997). The education of depressed primary care patients: What do patients think of interactive booklets and a video? Journal of Family Practice, 44, 562-571.

Schulz, R., \& Beach, S. R. (1999). Caregiving as a risk factor for mortality: The Caregiver Health Effects Study. Journal of the American Medical Association, 282, 2215-2219.

Schulz, R., Burgio, L., Burns, R., Eisdorfer, C., Gallagher-Thompson, D., Gitlin, L. N., et al. (2003). Resources for Enhancing Alzheimer's Caregiver Health (REACH): 
Overview, site-specific outcomes, and future directions. The Gerontologist, 43, 514520.

Schulz, R., \& Martire, L. (2004). Family caregiving of persons with dementia: Prevalence, health effects, and support strategies. American Journal of Geriatric Psychiatry, 12, 240-249.

Schulz, R., Martire, L., \& Klinger, J. (2005). Evidence-based caregiver interventions in geriatric psychiatry. Psychiatry Clinics of North America, 28, 1007-1038.

Schulz, R., O’Brien, A. T., Bookwala, J., \& Fleissner, K. (1995). Psychiatric and physical morbidity effects of dementia caregiving: Prevalence, correlates, and causes. The Gerontologist, 35, 771-791.

Sorensen, S., Pinquart, M., \& Duberstein, P. (2002). How effective are interventions with caregivers? An updated meta-analysis. The Gerontologist, 42, 356-372.

Steffen, A. M. (2000). Anger management for dementia caregivers: A preliminary study using video and telephone interventions. Behavior Therapy, 31(2), 281-299.

Steffen, A. M., Mahoney, D., \& Kelly, K. (2003). Capitalizing on technological advances to help distressed caregivers. In D. W. Coon, D. Gallagher-Thompson, \& L. Thompson (Eds.), Innovative interventions to reduce dementia caregivers' distress: A sourcebook and clinical guide. New York: Springer.

Steffen, A. M., \& Mangum, K. R. (2003). Distance-based interventions for depressed dementia family carers. The Clinical Psychologist, 7, 1-10.

Steffen, A. M., McKibbin, C., Zeiss, A., Gallagher-Thompson, D., \& Bandura, A. (1997). The revised scale for caregiver self-efficacy: Two reliability and validity studies. Journal of Gerontology: Psychological Sciences, 57, 74-86.

Tarlow, B., Wisniewski, S. R., Belle, S. H., Rubert, M., Ory, M., \& Gallagher-Thompson, D. (2004). Positive Aspects of Caregiving: Contributions of the REACH project to the development of new measures for Alzheimer's caregiving. Research on Aging, 26, 429-453.

Teri, L., Gibbons, L. E., McCurry, S. M., Logsdon, R. G., Buchner, D. M., Barlow, W. E., et al. (2003). Exercise plus behavioral management in patients with Alzheimer Disease: A randomized controlled trial. Journal of the American Medical Association, 290, 2015-2022.

Teri, L., Logsdon, R. G., Uomoto, J., \& McCurry, S. M. (1997). Behavioral treatment of depression in dementia patients: A controlled clinical trial. Journal of Gerontology: Psychological Sciences, 52B, P159-P166.

Teri, L., Truaz, P., Logsdon, R., Uomoto, J., Zarit, S., \& Vitaliano, P. (1992). Assessment of behavioral problems in dementia: The revised memory and behavior problem checklist. Psychology and Aging, 7, 622-631.

Toseland, R. W., McCallion, P., Smith, T., Huck, S., Bourgeois, P., \& Garstka, T. A. (2001). Health education groups for caregivers in an HMO. Journal of Clinical Psychology, 57, 551-570.

Vitaliano, P. P., Scanlan, J. M., Zhang, J., Savage, M. V., Hirsch, I. B., \& Siegler, I. C. (2002). A path model of chronic stress, the metabolic syndrome, and coronary heart disease. Psychosomatic Medicine, 64, 418-435.

Vitaliano, P. P., Young, H. M., \& Zhang, J. (2004). Is caregiving a risk factor for illness? Current Directions in Psychological Science, 13, 13-16.

Yeo, G. \& Gallagher-Thompson, D. (Eds.), Ethnicity and the dementias (2nd ed.). New York: Routledge/Taylor \& Francis Group.

Zarit, S. H., \& Zarit, J. M. (2007). Mental disorders in older adults. Family Caregiving (Chap. 13). New York: Guilford Press. 